\title{
Factors Differentiating Green Power Electricity User/Non-user Status in Australia
}

\author{
Yiming Tang \\ Macquarie University, Australia \\ Milind Medhekar \\ Macquarie University, Australia
}

\begin{abstract}
This study aims to identify factors differentiating users and non-users of GPE (Green Power Electricity) in Australia. The internet-based survey reached audience across Australia. The results show that consumers' environmental concern and ecologically conscious behaviour are key drivers of GPE purchase. Younger consumers are also more likely to be GPE users. Findings of this study bear significant implications for both government policymakers and GPE distributors and/or resellers. This study calls for increased effort in public education - especially of younger people - and in marketing campaigns to raise consumers' awareness of and concern for the environment. Further, it recommends that in order to maximize the adoption of GPE, and promotional campaign of GPE should be combined with other activities to educate the consumers of the benefits and the availability of GPE products and to promote ecologically friendly behaviors.
\end{abstract}

Keywords: Green Power Electricity, Environmental concern, Ecologically conscious behaviour, Australia

\section{Introduction}

Climate change in recent years has caused increasing concerns and posed a significant challenge to economic development in countries around the world. In response to this challenge, consumers around the world have demanded more environmentally friendly products. Recent research findings show consumer spending on green 
products is expected to reach US\$500 billion in recent years (Lander et al., 2007), clearly showing that green marketing has been gathering momentum. Among the growing list of environmentally friendly products is Green Power Electricity (GPE) electricity which is produced from renewable sources, including solar, wind, tidal wave, biomass and geothermal energy. GPE is regarded as socially desirable electricity due to its non-polluting nature (Swezey and Bird, 2000). The renewable energy sector has been forecasted to grow between $20-30 \%$ annually (Tilting at Windmills, 2006). There are currently 196 certified GPE providers in Australia National Green Power Accreditation Program Status Report, 2009) and GPE option has been available to $96 \%$ of the population since 2004 (Rundle-Thiele et al., 2008). Despite the increasing demand for GPE and the availability of technology to produce it, and the wide availability of GPE in Australia, the Australian electricity market is still dominated by coal-generated power, which accounts for $80 \%$ of production, while the renewable sources account for only 8\% (Australian Coal Association and Climate Institute, 2008), with an estimated retail market penetration rate slightly above 2\% (CIA, 2009, National Green Power Accreditation Program Status Report, 2009).

GPE provides an equal amount of utility as conventional electricity. Yet despite GPE being more costly than conventional electricity to produce, some consumers prefer GPE. So the obvious question from a marketing viewpoint is what the key factors are that promote GPE purchase. While there has been research on GPE marketing and GPE purchase in Australia, such effort has been limited to anecdotal experience via a case study of an electricity retailer (Rundle-Thiele et al., 2008). Little systematic research via large scaled empirical studies of electricity consumers is found in the literature to cover such an important subject in Australia. This unsatisfying situation paves the rationale for us to conduct this current research, representing a first empirical study via systematic research effort to investigate this subject in Australia. Specifically, the research question for our study is to identify the key factors that are associated with GPE purchase or non-purchase, thus, differentiating users and nonusers of GPE in Australia.

The rest of the paper is organized into four sections. In section II we critically review previous research literature on related topics, and in section III we develop our research hypotheses and measurements. In section IV we present our research methodology, including data collection, data analysis and the results of the hypothesis testing. In the last section $\mathrm{V}$, we discuss the academic contribution, practitioner implications and our conclusions.

\section{Literature Review}

Previous studies on consumers' engagement in their purchase of environmentally friendly products and/or services have identified a wide range of factors that influence such purchases, including ecological concern, ecological consciousness, subjective norms, perceived consumer effectiveness, consumer values, awareness and knowledge, and willingness to pay. 
Past research has found that environmental concern is positively and significantly correlated with environmentally friendly behaviour (Kinnear et al., 1974; Roberts, 1996; Roberts and Bacon, 1997), and consumers with higher levels of such concern are more likely to purchase green products (Banerjee and McKeage, 1994; Chan, 1999; Chan and Lau, 2000; Laroche et al., 2001; Straughan and Roberts, 1999). A strong positive link was also found between consumers' environmental consciousness and their purchase of environmentally friendly products such as biodegradable detergents and paper products (Schlegelmilch et al., 1996). Suchard and Polonsky (1991) stipulated that ecologically conscious consumers will try to protect the environment in various ways, by performing such activities as purchasing green products, engaging in recycling activities and favoring packaging made of recycled materials. Straughan and Roberts (1999) found that an environmentally friendly attitude is a precursor to environmentally friendly behaviour.

Triandis (1993) and McCarty and Shrum (1994) argue that collectivism values motivate people to transcend selfish concerns and promote the welfare of others and of nature. Therefore, collectivist people could be considered friendlier to the environment, with a tendency for restrictive conformity to social expectations. Schwartz (1992) labeled collective values as "self-transcendence", the tendency for restrictive conformity as "conservation", and individualist values as "selfenhancement" to reflect values motivating people to enhance their personal interests. Follows and Jobber (2000) found a positive association between self-transcendence and the likelihood of purchasing disposable diapers (an environmentally responsible product), and between consumers' conservation value, their attitude towards the environment and their purchase of environmentally responsible products. In addition, those holding stronger self-enhancement values are more likely to purchase a product with the lowest individual consequences, irrespective of their social implications. These results support earlier findings that individualistic people tend to be less friendly to the environment (McCarty and Shrum, 1994; Triandis, 1993). AoyagiUsui et al. (2003) find that in Japan, with its strong collectivism culture root, traditional way of thinking, such as honoring parents and elders and family security, etc, is welcomed. And green consumption behaviour and energy-saving is viewed as "contrary to the progressive value favoring economic growth and technological innovation" (Aoyagi-Usui et al., 2003, p. 29). As such, environmental value is positively associated with green-consumption behaviour in Japan.

Perceived effectiveness in solving environmental problems has also been linked to consumers' green products purchase. Samdahl and Robertson (1989) discovered that consumers expect intervention by regulatory bodies to deal with environmental problems. Roberts (1996) concluded that perceived consumer effectiveness was one of the strongest predictors of ecologically conscious consumer behaviour. On the other hand, consumers were unwilling to pay higher prices for green products if they believe the government and corporations, not individuals, should be responsible for solving ecological problems (Laroche et al., 2001).

Subjective norms relate to an individual's perception of an important referent's evaluation of his/her behaviour and the person's motivation to behave as per these evaluations. According to Fishbein and Ajzen (1975), as subjective norms become 
more favorable, a person's intention to perform certain behaviour increases. In another study, Ajzen and Fishbein (1980) pointed out that for co-operative behaviors, normative considerations are more important than attitude considerations. Cordano and Frieze (2000) applied Ajzen's Theory of Planned Behaviour to understand the behavioural preferences of 295 environmental managers, and found a positive relationship between environmental managers' assessment of subjective norms about environment regulation and their preference for implementing activities to reduce the sources of pollution. Thus, if a person believes that his/her referent groups expect $\mathrm{him} / \mathrm{her}$ to contribute towards solving environmental problems via environmentally friendly behaviour, such as buying "green products", s/he is more likely to do so.

Consumer knowledge has long been recognized as influencing all phases of a buying decision process. Rogers (1995) noted that the adoption process begins with the awareness of a problem (need), and the knowledge of the existence of an innovation (product). Consumers who identify environmental degradation as a serious social problem, and think that they need to do something about it, would be looking for green products as a solution. Batley et al. (2001) found that UK consumers' awareness level of GPE availability and its benefits is positively associated with their behaviour. Bang et al. (2000) found that lack of GPE knowledge was one reason for its slow uptake in the US. Similar finding is reported in a business case study in Australia as well (Rundle-Thiele et al., 2008)

Vlosky et al. (1999), in their study of ecologically certified wood products, found a positive relationship between environmental consciousness and willingness to pay a premium for such products. Furthermore, Farhar (1999) also discovered that the majority respondents in his research stated they were willing to pay a premium for GPE, hinting that people who are willing to pay more for green products should more likely to purchase such products. However, other empirical research reveals that a big gap often exists between the stated willingness to pay and actual purchase. For example, in a study of GPE pricing, Wiser (1998) discovered that less than $3 \%$ of residential customers actually joined the GPE programs, although $40-70 \%$ claimed willingness to pay. Such findings clearly show that willingness (intent) to pay for green products is not necessarily a reliable predictor of GPE purchase (behaviour).

Previous studies have also examined the association between consumers' demographics, their social-economic characteristics, with their ecologically conscious attitudes and/or their purchase behaviour towards green products. While age has shown equivocal associations (Anderson et al., 1974; Roberts, 1996; Samdahl and Robertson, 1989, Zimmer et al., 1994), younger people have been found to be more sensitive to environmental issues (Anderson and Cunningham, 1972; Kinnear et al., 1974; Roberts, 1995, 1996; Roberts and Bacon, 1997; Webster, 1975). A common explanation is that younger people, growing up in a time when environmental threats are increasingly seen as salient issues, are more sensitive to these issues (Straughan and Roberts, 1999). As far as gender is concerned, women are more likely than men to hold attitudes consistent with the green movement (Banerjee and McKeage, 1994; Laroche et al., 2001; Straughan and Roberts, 1999; Webster, 1975), and they are more likely to pay more for green products as well (Laroche et al., 2001). Income has also been examined as a predictor of ecologically conscious consumer behaviour, but the 
findings on the income-adoption of green products association show mixed directions (Anderson and Cunningham, 1972; Kinnear et al., 1974; Roberts, 1995, 1996; Roberts and Bacon, 1997; Zimmer et al., 1994). Several studies have also examined the relation of education levels with environmental concerns and environment friendly behaviour. Some of them found a positive association (Aaker and Bagozzi, 1982; Murphy et al., 1978; Roberts, 1996; Zimmer et al., 1994), although Samdahl and Robertson (1989) found a negative association. A possible explanation for the relationship between education level and environmentally conscious consumer behaviour is that educated people tend to have higher sensitivity to social problems, although no strong view has been found to explain the negative association.

\section{Research Hypotheses and Measurements}

Our literature review has uncovered a range of factors directly associated with purchase of green products. Yet, few of above cited studies have dealt with GPE purchase, and with only a case study (of a retailer) in Australia. As GPE belongs to the category of green products which would offer a solution to the current environmental degradation challenge, it is therefore logical to assume that findings of our literature review should also apply to GPE purchase in Australia.

Previous studies show that individual consumers' level of ecological concern is an important factor in determining his or her purchase of green products. Studies by Banerjee and McKeage (1994), Chan (1999), Chan and Lau (2000) and Laroche et al. (2001) show that higher level of environmental concern leads to green product purchases and participation in recycling programs. This positive association between environmental concern and the actual purchase behaviour of the green products should also apply to GPE, which is one of the green products available today. Thus, our first hypothesis (H1) states that a consumer is more likely to be a GPE user, the more concerned s/he is about the environment.

Several studies have found a positive association between individuals' environmental concern and their environmentally friendly behaviour (Kinnear et al., 1974; Roberts, 1996; Roberts and Bacon, 1997; Schlegelmilch et al., 1996). Ecologically conscious consumers will try to protect the environment via engagement in various activities and solutions, including purchasing green products, engaging in recycling activities, favoring packaging made of recycled materials, and similar activities (Suchard and Polonsky, 1991). One such solution is to purchase GPE. Thus, it is logical to believe that an environmentally conscious consumer, who is already involved in other environmentally friendly activities, is more likely to be a GPE user as well. Built on this logic, our second hypothesis (H2) states that a consumer is more likely to be a GPE user, the more engaged s/he is in ecologically conscious activities.

Collectivist people tend to be friendlier to the environment (McCarty and Shrum, 1994; Triandis, 1993). The pro-social domain of the collective values reflects the extent to which they motivate people to transcend their selfish concerns and promote the welfare of others and of nature. Schwartz (1992) labels this as "self-transcendent 
values", and argues that people holding stronger such value are more likely to be concerned about protecting the environment. Follows and Jobber (2000) found a positive relationship between self-transcendence and the likelihood of purchasing environmentally responsible products. Such findings suggest that self-transcendent values should promote GPE consumption as well, since the use of GPE benefits society in general. It is therefore reasonable to speculate that a positive associate should exist between consumers with pro-social self-transcendence values and their likelihood of use of GPE. Hence, our third hypothesis (H3) is that a consumer is more likely to be a GPE user, the higher self-transcendence value s/he hold.

Schwartz (1992) points out that people with conservatism values have a strong need for maintaining the status quo. Follows and Jobber (2000) found that consumers with high conservatism values had a less positive attitude towards the environment and were less likely to purchase environmentally responsible products. These findings can and should apply to GPE purchase as well. Consumers with high conservative values would be less likely to abandon the use of conventional electricity for something different and new, such as GPE, which does not bring higher level of utility to purchaser. The fourth hypothesis (H4) states, that a consumer is less likely to be a GPE user, the more conservation value s/he exhibits.

Schwartz (1992) re-named individualist values from the collective-individual dichotomy as 'self-enhancement' to reflect the values that motivate people to enhance their own personal interests. He created domains of hedonism (reflecting pleasure or sensuous gratification of oneself), achievement and power to be included in selfenhancement. Using these domains in their study, Follows and Jobber (2000) found that those who hold stronger self-enhancement values are more likely to purchase a product with the lowest individual consequences, regardless of its environmental friendliness. Such consumers seek products that are beneficial to themselves, irrespective of the social implications of using the products, supporting the arguments made by Triandis (1993) and by McCarty and Shrum (1994) that individualistic people tend to be less friendly to the environment. As the use of GPE would increase individual consequences in terms of paying higher prices without receiving any additional functional benefits from it, individuals holding higher self-enhancement values seem less likely to be users of GPE. As such, our fifth hypothesis (H5) is that a consumer is less likely to be a GPE user, the stronger self-enhancement values s/he holds.

Subjective norms relate to an individual's perception of an important referent's (e.g. a friend's or family member's) evaluation of one's behaviour and the person's motivation to behave in line with these evaluations. According to Fishbein and Ajzen (1980), as subjective norms become more favorable, a person's propensity to certain behaviour increases. For co-operative behaviors, normative considerations are more important than an individual's attitude. If people can be influenced by their referent groups which expect them to perform according to the group's expectations, then there is a greater probability of their fulfilling those expectations. Hence, if people believe that their referent groups, such as family, close friends or colleagues, expect them to contribute towards solving environmental problems via environmentally friendly behaviour (such as buying 'green products'), they are therefore more likely to 
use such products. While subjective norms construct has been applied in previous consumer behavioural studies, little evidence is found in the literature to link its application to the purchase of a specific environmentally friendly product such as GPE. Given that the use of GPE benefits society in general, it is expected that it would become a social norm in future to do so. The normative influences associated with what benefits society should therefore play a very positive role in the likelihood of GPE purchase. It is based on this assumption that our six hypothesis (H6) states that a consumer is more likely to be a GPE user, if s/he thinks that her/his referent groups expect him/her to do so.

Findings from previous studies also show that perceived consumer effectiveness (PCE) is not only associated with consumers' ecological consciousness (Ellen et al., 1991; Kinnear et al., 1974), but also linked to their purchase behaviour (Samdahl and Robertson, 1989; Roberts, 1996). Laroche et al. (2001) found that consumers who believe that it is the responsibility of governments and corporations, rather than individuals, to solve ecological problems, are not willing to pay more for green products. While the above cited studies are not related to GPE, it is logical to expect that a similar rationale should be applicable to GPE purchase as well. Given that there is no apparent additional functional advantage to consumers for choosing GPE over electricity produced from conventional sources, those consumers who strongly believe that they are individually less influential in protecting the environment, and that it is the government's and/or corporations' responsibility to solve the ecological problems, are less likely to be GPE users. Therefore, our seventh hypothesis (H7) states that $a$ consumer is less likely to be a GPE user, if s/he feels that individuals cannot be effective in solving environmental problems.

Rogers (1995) seminal research on product adoption clearly demonstrates that product awareness is a critical factor in early adoption of a new product. Consumers who identify environmental degradation as a serious social problem, and think that they need to do something about it, would be looking for various solutions. Therefore, if consumers are aware of the availability of GPE in the market, and that adopting GPE can help to solve the environmental problems, they may consider GPE purchase. Finding of a business case study in Australia shows, from the opposite angle, that low awareness of GPE in Australia has been a key reason for the slow adoption and low penetration of GPE in Australia (Rundle-Thiele et al., 2008). These evidences show that awareness of the existence of a product like GPE appears to be a precursor to its use. Thus, electricity consumers who have information about GPE are most likely to be its users. Hence, our eighth hypothesis (H8) states that a consumer is more likely to be a GPE user, if s/he is aware of its availability.

Our literature survey reveals that several studies have investigated consumers' willingness to pay a premium for environmentally friendly products, but their findings show a gap between stated intent and purchase, indicating a very unclear picture of the association between consumers' willingness to pay and actual purchase of green products (Farhar, 1999; Suchard and Polonsky, 1991; Vlosky et al., 1999; Wiser, 1998), indicating that willingness to pay is not a reliable predictor of green consumption behaviour. As such, we have decided to exclude this factor from the current study. Many studies have also investigated the association between 
consumers' purchase of green products and their demographic and social-economic characteristics, including age (Anderson and Cunningham, 1972; Anderson et al., 1974; Kinnear et al., 1974; Roberts, 1995, 1996; Roberts and Bacon, 1997; Webster, 1975; Zimmer et al., 1994), Gender (Banerjee and McKeage, 1994; Laroche et al., 2001; Straughan and Roberts, 1999; Webster, 1975), education (Aaker and Bagozzi, 1982; Kinnear et al., 1974; Murphy et al., 1978; Roberts, 1996; Samdahl and Robertson, 1989; Zimmer et al., 1994), and income (Anderson and Cunningham, 1972; Kassarjian, 1971; Kinnear et al., 1974; Roberts, 1995, 1996; Roberts and Bacon, 1997; Straughan and Roberts, 1999; Zimmer et al., 1994). However, these studies have produced mixed results in terms of the associations between consumers' demographic and social-economic factors and their green products purchase. As a result, we have decided to include the various demographic characteristics as control variables in this research without formulating a specific hypothesis for each of these factors.

\section{Methodology}

In this study, the GPE purchase behaviour is measured using GPE user and non-user status. Measures capturing the other variables covered in the research hypotheses are adopted from the relevant studies covered in our literature review. Table 1 contains our research hypotheses and corresponding measures. Other demographic variables are adopted from the literature.

Table 1 Research Hypotheses and Scale Measurements

\begin{tabular}{|l|l|}
\hline \multicolumn{1}{|c|}{ Research Hypotheses } & \multicolumn{1}{c|}{ Measures } \\
\hline $\begin{array}{l}\text { H1. A consumer is more likely to } \\
\text { be a user of GPE, the more } \\
\text { environmentally conscious s/he } \\
\text { is. }\end{array}$ & $\begin{array}{l}\text { Environmental consciousness (EC): 12 items, 5-point } \\
\text { scale: 5 = strongly agree, 1 = strongly disagree; } \\
\text { Adapted, based on Straughan and Roberts (1999) }\end{array}$ \\
\hline $\begin{array}{l}\text { H2. A consumer is more likely to } \\
\text { be a user of GPE, the more s/he is } \\
\text { engaged in ecologically conscious } \\
\text { consumer behaviour. }\end{array}$ & $\begin{array}{l}\text { Ecologically conscious consumer behaviour (ECCB): } \\
\text { 22 items, 5-point scale: 5 = Always True, 1 = Never } \\
\text { True; Adapted, based on Straughan and Roberts (1999) }\end{array}$ \\
\hline $\begin{array}{l}\text { H3. A consumer is more likely to } \\
\text { adopt GPE, the stronger self- } \\
\text { transcendence values s/he holds. }\end{array}$ & $\begin{array}{l}\text { Self-transcendence Scale (STS): 4 items, 7-point scale: } \\
\text { 7= Extremely Important, 1 = Not important); Adopted } \\
\text { from Follows and Jobber (2000) }\end{array}$ \\
\hline $\begin{array}{l}\text { H4. A consumer is less likely to } \\
\text { be a user of GPE, the more } \\
\text { conservation s/he exhibits. }\end{array}$ & $\begin{array}{l}\text { Conservation Scale (CS): 3 items, 7-point scale: 7 } \\
\text { Extremely Important, 1 = Extremely Unimportant; } \\
\text { Adopted from Follows and Jobber (2000) }\end{array}$ \\
\hline $\begin{array}{l}\text { H5. A consumer is less likely to } \\
\text { be a user of GPE, the stronger } \\
\text { self-enhancement values s/he } \\
\text { holds. }\end{array}$ & $\begin{array}{l}\text { Self-enhancement Scale (SES): 3 items, 7-point scale: } \\
7=\text { Extremely Important, 1 = Extremely Unimportant; } \\
\text { Adopted from Follows and Jobber (2000) }\end{array}$ \\
\hline $\begin{array}{l}\text { H6. A consumer is more likely to } \\
\text { be a user of GPE if s/he thinks } \\
\text { that her/his referent groups expect } \\
\text { him/her to do so. }\end{array}$ & $\begin{array}{l}\text { Subjective Norms (SN): 4 items, 5 point scale: 5 = } \\
\text { Strongly Agree, 1 = Strongly Disagree; Adapted, based } \\
\text { on Ajzen and Fishbein (1980) }\end{array}$ \\
\hline
\end{tabular}




\begin{tabular}{l|l|}
$\begin{array}{l}\text { H7. A consumer is less likely to } \\
\text { be a user of GPE if s/he thinks } \\
\text { that individuals cannot be } \\
\text { effective in solving the } \\
\text { environmental problems. }\end{array}$ & $\begin{array}{l}\text { Perceived Consumer Effectiveness (PCE): 4 items, 5- } \\
\text { point scale: 5 = Strongly Agree, 1 = Strongly Disagree) } \\
\text { Straughan and Roberts (1999) }\end{array}$ \\
\hline $\begin{array}{l}\text { H8. A consumer is more likely to } \\
\text { be a GPE user, if s/he is aware of } \\
\text { its availability. }\end{array}$ & $\begin{array}{l}\text { Consumer's knowledge (CK): awareness (Yes/ No) of } \\
\text { GPE's availability in Australia }\end{array}$ \\
\hline
\end{tabular}

Prior to the main study, we conducted a pilot study to test the measures adopted from previous studies via a convenience sample of 23 households selected from the Sydney metropolitan area. Personal interviews were conducted with selected households. The pilot study results were incorporated into the survey used for the main study.

Data collection for the main study was initially planned via a mail survey among existing customers of key Australian electricity retailers. Considerable effort was taken over a six-month period in negotiating with several interested electricity retailers across the country as potential research sites. Unfortunately, such effort failed to produce an acceptable agreement from the electricity retailers, due to their proposed exclusive ownership of the research data and their legal restrictions on publishing subsequent research findings. As a result, an open online survey was carried for the main data collection as a compromise. A user-friendly web-based questionnaire was developed using the static (or scrollable) approach advocated by Dillman (2000), consisting of single HTML format, which survey respondents could easily scroll up and down. This aims to minimize invalid responses. The survey takes approximately 20 minutes for a respondent to complete the survey. A notification was posted to the websites of NSW Dept of Energy, Utilities and Sustainability (DEUS), Clean-Up Australia, and Climate Action Network Australia (CANA) groups, reaching approximately 2750 people Australia-wide via a broadcasting email newsletter. Screening questions are used to ensure the online survey is completed by our targeted research subjects, who are decision-makers of residential electricity purchases. A total of 220 surveys were returned over a four-month period, of which 210 were deemed usable. The estimated response rate is of $7.64 \%$.

\section{Results, Discussion, Limitations and Future Research Directions}

Prior to data analysis, both reliability and validity tests were carried out on the multiple-item measurement scales used in the main survey. Reliability is an assessment of the degree of consistency between a variable and its multiple measurements, or the correlation between a measure and the construct itself (Peter, 1979). Our reliability test results show that the Cronbath's coefficient alpha values for all the measurements scales range from 0.676 to 0.946 , indicating acceptable reliability of these measures (Hair et al., 1998; Nunnally, 1978; Peter, 1979). Whereas reliability relates to the consistency of the measure(s), validity is the extent to which a scale or set of measures accurately represents the concept of interest (Hair et al., 
1998). Confirmatory factor analysis was undertaken to establish the validity of the psychographic variables through the Structural Equation Modeling (SEM) using AMOS (Arbuckle and Wothke, 1999). Results show that CMIN/DF ratios for the scales are within the acceptable 1-3 range (Cheung and Rensvold, 2002), CFI and TLI index values of $>0.95$ (Hu and Bentler, 1999) and of RMSEA values up to 0.10 (Cunningham et al., 2004; Wang et al., 2005), with the exception of the environmental consciousness scale. Rectification of this scale would require a deletion of five of the 12 items used within the original scale, a substantial deviation from the measurement construction and from the theoretical foundation of the scale. Consequently, it was decided to keep the scale composition unchanged.

When a dependent variable is discrete, both logit analysis and discriminant analysis can be utilized to assess the level of association between the dependent variable and the independent variables (Hair et al., 1998; Sharma, 1996). Between the two methods, logit analysis exhibits several advantages over discriminant analysis in that it does not rely on any assumption about the distribution of the independent variables, an advantage over linear regression as well, and that its output is similar to linear regression with straightforward statistical tests. Several forms of logit analysis exist, including binomial, multinomial and ordered logit (Greene, 2003; McCullagh and Nelder, 1989). When the dependent variable is dichotomous, binomial logit analysis is preferred (Afifi and Clark, 1984; Hair et al., 1998). This applies to 'user/non-user status,' the response variable of our study. Therefore, we applied binomial logit analysis for our hypotheses testing, and the model results are summarized in Table 2.

Table 2 Research Hypotheses Test Results

\begin{tabular}{|c|c|c|c|c|c|c|}
\hline $\begin{array}{c}\text { Variable } \\
\text { (hypothesis) }\end{array}$ & B & S.E. & Wald & df & Sig. & $\operatorname{Exp(B)}$ \\
\hline $\mathrm{EC}(\mathrm{H} 1)$ & 0.921 & 0.364 & 6.382 & 1 & $0.012 * *$ & 2.511 \\
\hline ECCB (H2) & 0.630 & 0.217 & 8.468 & 1 & $0.004 * * *$ & 1.879 \\
\hline SELTRNSDNC(H3) & 0.074 & 0.098 & 0.562 & 1 & 0.453 & 1.076 \\
\hline CONSERVTN(H4) & -0.151 & 0.103 & 2.149 & 1 & 0.143 & 0.860 \\
\hline SELENHMT(H5) & -0.166 & 0.084 & 3.915 & 1 & $0.048 * *$ & 0.847 \\
\hline $\mathrm{SN}(\mathrm{H} 6)$ & -0.014 & 0.058 & 0.058 & 1 & 0.810 & 0.986 \\
\hline $\mathrm{PCE}(\mathrm{H} 7)$ & -0.023 & 0.045 & 0.264 & 1 & 0.608 & 0.977 \\
\hline AGE1 & 1.311 & 0.688 & 3.629 & 1 & $0.057^{*}$ & 3.709 \\
\hline AGE2 & 0.502 & 0.599 & 0.701 & 1 & 0.402 & 1.652 \\
\hline GENDER & 0.109 & 0.421 & 0.067 & 1 & 0.796 & 1.115 \\
\hline EDUCAT1 & 0.286 & 0.732 & 0.152 & 1 & 0.696 & 1.331 \\
\hline EDUCAT2 & 0.309 & 0.457 & 0.455 & 1 & 0.500 & 1.361 \\
\hline INCOME1 & 0.331 & 0.522 & 0.401 & 1 & 0.526 & 1.392 \\
\hline INCOME2 & -0.488 & 0.561 & 0.759 & 1 & 0.384 & 0.614 \\
\hline
\end{tabular}

Our hypothesis tests have produced significant and very interesting results. First, the test results show that our first hypothesis $(\mathrm{H} 1)$ on the association between a consumer's environmental consciousness and his/her GPE purchase behaviour is 
supported. In other words, the more a respondent is concerned about environment, the more likely s/he is a GPE user. Such a result clearly shows that those who are concerned about the environment and its deterioration are more likely to be GPE users. This finding is consistent with previous research findings that people who exhibit strong environmental concern are more inclined to purchase green products (Banerjee and McKeage, 1994; Chan, 1999; Chan and Lau, 2000; Laroche et al., 2001; Straughan and Roberts, 1999). Furthermore, the logit output shows that the odd ratio for the EC (environmental concerns) variable is 2.51, suggesting that if other things are equal; a person exhibiting higher level of EC is 2.5 times more likely to be a GPE user than a person exhibiting a lower level of EC. Such a result clearly demonstrates that the level of EC of a consumer is a strong predictor of his/her GPE purchase behaviour.

Second, the test results show our second hypothesis (H2) with regard to the association between a consumer's ecologically conscious consumer behaviour and his/her GPE user status is also supported. This finding demonstrates that those who have already actively practiced ecological conscious consumer behaviour are also most likely to purchase GPE as well. Such an association is logical, since undertaking environmentally friendly activities expresses a person's environmental consciousness. Therefore, a person with such an attitude is more likely to attempt to reduce further damage to the environment, and sees purchase of GPE as another means towards this end. Again, this finding is consistent with previous studies' results (Kinnear et al., 1974; Roberts, 1995; Roberts and Bacon, 1997; Schlegelmilch et al., 1996; Suchard and Polonsky, 1991). The logit analysis result also shows that the odds ratio for this variable is 1.88 , indicating that, when other things are equal, a person already engaged in environmentally conscious consumer behaviour is 1.88 times more likely to be a user of GPE than a person who has not. Once again our study provides further supporting evidence to show that a person's level of ECCB is another strong predictor of his/hers purchase behaviour of GPE.

Third, our test results further show that the fifth hypothesis (H5) relating to the assumed association between respondent's self-enhancement value and his/hers GPE user status is supported as well. This finding show that those who exhibit a higher level of self-enhancement sentiment are less likely to be GPE users. In other words, the more selfish a consumer is, the less likely s/he will adopt and purchase GPE. Selfenhancement represents a self-centred orientation towards a person's physical needs and successes. This individualistic concern tends to put individual consequences of consumption ahead of social consequences, which might explain our finding of the negative association between self-enhancement and GPE user status. Again this finding supports results of previous studies, that people with such values are inclined to maximise their individual benefit (Schwartz, 1992), and are less likely to purchase and use GPE (Follows and Jobber, 2000), since purchase of GPE does not directly provide additional benefits to these individuals. The odds ratio for the selfenhancement variable is 0.847 , weaker than the above two accepted hypotheses. It suggests that, when other things are equal, a consumer exhibiting higher high selfenhancement values is 0.85 times less likely to be a GPE user than a person holding a lower such value. This result shows a consumer's SE value is yet another significant 
predictor of his/her purchase behaviour towards GPE, but at a lesser degree as compared with the consumer's EC and ECCB levels.

Fourth, our test results further show that the following four hypotheses are not found to be significantly associated with GPE user status. Specifically, (H3) a respondent's self-transcendence value, (H4) his/her conservation attitude, (H6) his/her perceived reference group preferences, (H7) his/her perceived effectiveness in solving environmental problems, are not found to be significantly associated with his/her GPE user status.

Our eighth hypothesis (H8) relates to a respondent's awareness of GPE's availability. It is self-evident that GPE users are aware of its availability from electricity suppliers and so the dichotomous measure (Yes/No) to the question on GPE awareness is pertinent only to the non-user group. Consequently, H8 was tested not via the binomial logistic model but via a chi-square test of the association between AWARENESS and a surrogate variable of "willingness-to-subscribe" (divided into "willing" or non-willing subgroups). The results show that $83.7 \%$ respondents within the non-awareness group are willing to subscribe GPE, which is compared to $77.6 \%$ respondents within the awareness group $(p=0.400)$. As such, awareness of GPE availability is not found to significantly associate with GPE purchase.

Fifth, among the respondents' demographic and social-economic factors, a consumer's age is found to be marginally $(p<.10)$ associated with his/her GPE user status. Our logistic regression model shows that GPE users in our sample are slightly younger than the non-users. This evidence supports previous research findings that younger people have a higher sensitivity to environmental issues (Anderson and Cunningham, 1972; Kinnear et al., 1974; Roberts, 1995 1996; Roberts and Bacon, 1997; Straughan and Roberts, 1999; Webster, 1975). It is logical to speculate that, since younger generations are experiencing increasing environmental degradation in their times, they are naturally very concerned about the impact of such a challenge on their future. As such, they may be more likely to adopt GPE as one of their counteractions facing the challenge of environmental degradation. Other demographic and social-economic characteristics included in the study are not found to have a significant association with his/her adoption of GPE. Despite of such findings, some test results deserve further analysis. Specifically, the coefficient for gender variable (male $=0$, female $=1$ ) is 0.109 , showing increased odds that a GPE user being a female than a male, which is consistent with findings by Straughan and Roberts (1999), and by Laroche et al. (2001).

\section{Table 3 Respondents’ GPE User Status and their Demographics}

\begin{tabular}{|c|c|c|c|c|c|}
\hline $\begin{array}{c}\text { GPE user } \\
\text { status }\end{array}$ & Sex $(\mathrm{m} / \mathrm{f})$ & $\begin{array}{c}\text { Average } \\
\text { Age }\end{array}$ & $\begin{array}{c}\text { Family } \\
\text { size }\end{array}$ & Education level & $\begin{array}{c}\text { Family } \\
\text { income }\end{array}$ \\
\hline User & $58 \% / 42 \%$ & 38.6 & $3-4$ & $\begin{array}{c}\text { Trades to } \\
\text { Diploma/Graduate }\end{array}$ & $50-60 \mathrm{k}$ \\
\hline Non-user & $71 \% / 29 \%$ & 40.2 & $3-4$ & Diploma - Graduate & $60 \mathrm{k}+$ \\
\hline
\end{tabular}


This study makes several contributions. First, it fills a gap within the field of green marketing research by covering GPE in Australia. Results relating to the accepted and partially accepted hypotheses bring in additional empirical evidence from a new product and in a different geographic location. Therefore, findings of our study add knowledge to the field of green marketing research and thus, further strengthen the current theory on green marketing. Second, the study establishes a significant and positive association between a consumer's GPE user status, his/her level of environmental concerns, and his/her level of ecologically conscious behaviour, as well as a significant but negative association between a consumer's self-enhancement value and his/her GPE user status. Third, it shows that younger generations are more likely to be GPE users, due probably to their increased level of awareness and concerns over the impact of environmental degradation on their future.

The above contributions bear significant implications for both GPE providers and governments at various levels. First, significant effort is needed in conducting public education campaigns in order to raise consumers' awareness and level of concern about the environment. Second, such campaigns should combine with other activities promoting ecologically friendly behaviors to maximize the impact. Third, while such campaigns should target all age groups, public education needs to start early to achieve an enduring effect, and more effort is needed in pursuing older audiences as well. Given the fact that green marketing theory has been developed and tested via empirical studies in countries other than Australia, the implications of the findings of this study to policy makers and to practitioners should be seen as having more significance to today's society in terms of finding ways to promote and increase GPE purchase.

This study might suffer from possible sample biases. First, the proportion of GPE users in our sample is higher than the market penetration rate, which is probably due to some of the people who received notification of the online survey are directly and/or indirectly involved in environment protection related fields and/or activities. However, given that this study's key objective is to discover factors differentiating GPE users from non-users, and given the low GPE penetration rate in the Australian electricity market and the anticipated low response rate of online survey, it was decided that we needed to target GPE users in order to obtain sufficient numbers of users for the data analysis and hypotheses testing. Second, our sample size is relatively small, which is a result of the time and budget constraints as well as the legal restrictions we faced on the potential publication of the research findings. Future studies should try to further address these issues by collecting data from a larger sample following a random sampling method.

The response rate of our study seems relatively low, although our study is the first of its kind on GPE purchase using internet survey in Australia, little previous information is available for comparison. Several factors are believed to have contributed to the relatively low response rate. First, the low penetration rate of renewable energy in Australia energy market might suggest a lower level of interest on the subject in the country, which would be a key contributor. Second, Research findings indicate that web-based surveys have lower response rate than mail survey 
(Cole, 2005), and that there has also been an overall increase of non-response rate to web-based surveys in recent years (Sax et al., 2003). Furthermore, Australia's internet penetration rate was reported to be around 79\% (Miniwatts Marketing Group, 2008). So, a good proportion of the Australian population still has no access to internet, further restricting participation of a web-based survey. And third, despite of assurances of anonymity and confidentiality in the announcement posted on the websurvey site, some people might still have doubts and therefore might have refrained from participating, further contributing to the lower return rate. Future studies should make additional effort to draw evidence from larger samples, and to utilize advance notice and follow ups in order to increase their survey return rates. Despite of these potential limitations, this study represents a first step towards systematic research effort in the field of green marketing research on GPE purchase in Australia.

\section{References}

Aaker, D.A. and Bagozzi, R.P. (1981), "Attitude toward public policy alternatives to reduce air pollution", Advances in Consumer Research, vol. 8, no. 1, pp. 616-621.

Afifi, A.A. and Clark, V. (1984), Computer-aided Multivariate Analysis, Lifetime Learning Belmont, CA.

Ajzen, I. and Fishbein, M. (1980), Understanding Attitudes and Predicting Social Behaviour, Prentice-Hall, New Jersey, NJ.

Anderson, W.T. Jr. and Cunningham, W.H. (1972), "The socially conscious consumer", Journal of Marketing, vol. 36, no. 7, pp. 23-31.

Anderson, W.T. Jr., Henion, K.E. and Cox III, E.P. (1974), "Socially vs ecologically responsible consumers", AMA Combined Conference Proceedings, vol. 36, pp. 304-311.

Aoyagi-Usui, M., Vinken, H. and Kuribayashi, A., (2003), "Pro-environmental attitudes and behaviors: An international comparison”, Human Ecology Review, vol. 10, no. 1, pp. 23-31.

Arbuckle, J.L. and Wothke, W. (1999), AMOS 4.0 User's Guide, Smallwaters Chicago, IL.

Australian Coal Association and Climate Institute (2008), The Sydney Morning Herald, 10-11 May 2008, p. 27.

Banerjee, B. and McKeage, K. (1994), "How green is my value: Exploring the relationship between environmentalism and materialism", Advances in Consumer Research, vol. 21, no. 1, pp. $147-152$.

Bang, H.K., Ellinger, A.E., Hadjimarcou, J. and Traichal, P.A. (2000), "Consumer concern, knowledge, belief and attitude toward renewable energy: An application of reasoned action theory", Psychology and Marketing, vol. 17, no. 6, pp. 449-468.

Batley, S.L., Colbourne, D., Felming, P.D. and Urwin, P. (2001), "Citizens versus consumer: Challenges in the UK green power market", Energy Policy, vol. 29, no. 6, pp. 479-487. 
Chan, K. (1999), "Market segmentation of green consumers in Hong Kong", Journal of International Consumer Marketing, vol. 12, no. 2, pp. 7-24.

Chan, R.Y.K. and Lau, L.B.Y. (2000), "Antecedents of green purchases: A survey in China", Journal of Consumer Marketing, vol. 17, no. 4, pp. 338-357.

CIA (2009), “The world's factbook". Retrieved 14 June 2009, from https://www.cia.gov/library/publications/the-world-factbook/

Cheung, G.W. and Rensvold, R.B. (2002), "Evaluating goodness-of-fit indexes for testing measurement invariance", Structural Equation Modeling, vol. 9, no. 2, pp. 233-255.

Cole, S.T. (2005), "Comparing mail and web-based survey distribution methods: Results of surveys to leisure travel retailers", Journal of Travel Research, vol. 43, no. 4, pp. 422-430.

Cordano, M. and Frieze, I.H. (2000), "Pollution reduction preferences of U.S. environmental managers: Applying Ajzen's theory of planned behaviour", Academy of Management Journal, vol. 43, no. 4, pp. 627-641.

Cunningham, E.G., Werner, S.C. and Firth, N.V. (2004), "Control belief mediators of school connectedness and coping outcomes in middle adolescence", Australian Journal of Guidance and Counseling, vol. 14, no. 2, pp. 139-150.

Farhar, B.C. (1999), "Willingness to pay for electricity from renewable resources: A review of utility market research", National Energy Laboratory, Department of Energy, U.S.A.

Fishbein, M. and Ajzen, I. (1975), Belief, Attitude, Intention and Behaviour, Addison-Wesley, Philippines.

Follows, S.B. and Jobber, D. (2000), "Environmentally responsible purchase behaviour: A test of a consumer model", European Journal of Marketing, vol. 34, no. 5/6, pp. 723-746.

Greene, W.H. (2003), Econometric Analysis, 5th ed., Prentice Hall, Upper Saddle River, NJ.

Hair, J.F. Jr., Anderson, R.E., Tatham, R.L. and Black, W.C. (1998), Multivariate Analysis, 5th ed., Prentice-Hall, New Jersey, NJ.

Hu, L. and Bentler, P.M. (1999), "Cutoff criteria for fit indexes in covariance structure analysis: Conventional criteria versus new alternatives", Structural Equation Modeling, vol. 6, no. 1, pp. 1-55.

Kinnear, T.C., Taylor, J.R. and Ahmed, S.A. (1974), "Ecologically concerned consumers: Who are they?" Journal of Marketing, vol. 38, no. 2, pp. 20-24.

Landor Associates, Penn, Schoen \& Berland Associates and Cohn \& Wolfe (2007), 2007 Green Power Brands Survey. Retrieved from http://www.environmentalleader.com/2007/09/28/

Laroche, M., Bergeron, J. and Barbaro-Forleo, G. (2001), "Targeting consumers who are willing to pay more for environmentally friendly products", Journal of Consumer Marketing, vol. 18 , no. 6 , pp. 503-520. 
McCarty, J.A. and Shrum, L.J. (1994), "The recycling of solid wastes: Personal values, value orientations and attitudes about recycling as antecedent of recycling behaviour", Journal of Business Research, vol. 30, no. 1, pp. 53-62.

McCullagh, P. and Nelder, J.A. (1989), Generalized Linear Models, 2nd ed., Chapman and Hall, London.

Miniwatts Marketing Group (2008), "Internet world stats: Usage and population". Retrieved 10 June 2009, from http://www.internetworldstats.com/top25.htm

Murphy, P.E., Kangun, N. and Locander, W.B. (1978), "Environmentally concerned consumers - racial variations", Journal of Marketing, vol. 42, no. 4, pp. 61-66.

National Green-power Accreditation Program Status Report (2009), 1 January - 31 March 2009. Retrieved 15 June 2009, from

http://www.greenpower.gov.au/admin/file/content13/c6/greenpower_quarter_01_final.pdf

Nunnally, J.C. (1978), Psychometric Theory, McGraw-Hill, New York, NY.

Peter, J.P. (1979), "Reliability: A review of basic issues and marketing practice", Journal of Marketing Research, vol. 16, no. 1, pp. 6-17.

Roberts, J.A. (1995), "Profiling levels of socially responsible consumer behaviour: A cluster analytic approach and its implications for marketing", Journal of Marketing Theory and Practice, vol. 3, no. 4, pp. 97-117.

Roberts, J.A. (1996), "Green consumers in the 1990s: Profile and implications for advertising", Journal of Business Research, vol. 36, no. 3, pp. 217-231.

Roberts, J.A. and Bacon, R. (1997), "Exploring the stable relationship between environmental concern and ecologically conscious consumer behaviour", Journal of Business Research, vol. 40, no. 1 , pp. 79-89.

Rogers, E.M. (1995), Diffusion of Innovations, 4th ed., Free Press, New York, NY.

Rundle-Thiele, A., Paladino, A. and Apostol, S.A. (2008), "Lessons learned from renewable electricity marketing attempts: A case study”, Business Horizons, vol. 51, no. 3, pp. 181-190.

Samdahl, D.M. and Robertson, R. (1989), "Social determinants of environmental concern: Specification and test of the model", Environment \& Behaviour, vol. 21, no. 1, pp. 57-81.

Sax, L.J., Gilmartin, S. K. and Bryant, A.N. (2003), “Assessing response rates and nonresponse bias in web and paper surveys", Research in Higher Education, vol. 44, no. 4, pp. 409-432.

Schlegelmilch, B.B., Bohlen, G.M. and Diamantopoulos, A. (1996), "The link between green purchasing decisions and measures of environmental consciousness", European Journal of Marketing, vol. 30, no. 5, pp. 35-55. 
Schwartz, S.H. (1992), "Universals in the content and structure of values: Theoretical advances and empirical tests in 20 countries", Advances in Experimental Social Psychology, vol. 25, pp. 1-65.

Straughan, R.D. and Roberts, J.A. (1999), "Environmental segmentation alternatives: A look at green consumer behaviour in the new millennium", Journal of Consumer Marketing, vol. 16 , no. 6 , pp. 558-575.

Suchard, H.T. and Polonsky, M.J. (1991), "A theory of environmental buyer behaviour and its validity: The environmental action-behaviour model", AMA Summer Educators' Conference Proceedings, vol. 2, pp. 187-201.

Swezey, B. and Bird, L. (2000), Green Power Marketing in the United States: A Status Report, 5th ed., National Renewable Energy Laboratory, Department of Energy, U.S.A.

"Tilting at windmills" (2006), The Economist, 381(8504), 16 Nov 2006, p. 83.

Triandis, H.C. (1993), "Collectivism and individualism as cultural syndromes", CrossCultural Research, vol. 27, no. 3/4, pp. 155-180.

Vlosky, R.P., Ozanne, L.K. and Fontenot, R.J. (1999), “A conceptual model for US consumer willingness-to-pay for environmentally certified wood products", Journal of Consumer Marketing, vol. 16, no. 2, pp. 122-136.

Wang, Y., Ye, F., Jackson, G., Rodgers, R. and Jones, S. (2005), "Development of student service-learning course survey (SSLCS) to measure service-learning course outcomes", Association for Institutional Research Publications, vol. 3, no. 21, pp. 1-15.

Webster, F.E. Jr. (1975), "Determining the characteristics of the socially conscious consumer", Journal of Consumer Research, vol. 2, no. 3, pp. 188-196.

Wiser, R.H. (1998), "Green power marketing: Increasing consumer demand for renewable energy”, Utility Policy, vol. 7, no. 2, pp. 107-119.

Yam-Tang, E.P.Y. and Chan, R.Y.K. (1998), "Purchasing behaviors and perceptions of environmentally harmful products", Marketing Intelligence \& Planning, vol. 16, no. 6, pp. 356-362.

Zimmer, M.R., Stafford, T.F. and Stafford, M.R. (1994), "Green issues: Dimensions of environmental concern”, Journal of Business Research, vol. 30, no. 1, pp. 63-74. 